\title{
HUBUNGAN DISMENOREA TERHADAP AKTIVITAS BELAJAR MAHASISWI DI PRODI DIII KEBIDANAN STIK IMMANUEL BANDUNG
}

\author{
Hani Triana \\ Sekolah Tinggi Ilmu Kesehatan Immanuel \\ huny_1509@yahoo.com
}

\begin{abstract}
Abstrak
Nyeri haid (dismenore) merupakan salah satu gangguan saat menstruasi dan salah satu aktivitas yang terganggu akibat terjadinya dismenore pada mahasiswi adalah aktivitas belajar. Survei pendahuluan yang dilakukan peneliti menunjukan bahwa mahasiswi yang mengalami dismenore merasa tidak nyaman dan tidak bersemangat dalam proses pembelajaran, sehingga hal ini membuat mahasiswi tidak masuk perkuliahan. Penelitian ini bertujuan untuk mengetahui hubungan Dismenore terhadap aktivitas belajar mahasiswi di Prodi DIII Kebidanan STIK Immanuel Bandung. Jenis penelitian ini adalah penelitian kuantitatif dengan desain cross sectional, populasi dalam penelitian ini adalah mahasiswi yang mengalami dismenore yaitu sebanyak 28 orang. Berdasarkan analisi data diperoleh Dari 28 orang mahasiswi yang aktivitas belajarnya terganggu karena mengalami dismenore adalah sebanyak 11 orang $(39,3 \%)$ sedangkan mahasiswi yang aktivitas belajarnya tidak terganggu saat mengalami dismenore adalah sebanyak 17 orang $(60,7 \%)$. Dari hasil jumlah mahasiswi tersebut ditemukan bahwa dari 11 orang mahasiwa yang aktivitasnya terganggu adalah mahasiswi yang mengalami dismenore dengan intensitas nyeri berat. Analisis data menggunakan chi square dengan hasil penelitian menunjukan bahwa terdapat hubungan yang signifikan antara kejadian dismenore terhadap aktivitas keluarga $(0,000<0,05)$. Kesimpulan dari hasil penelitian ini yaitu terdapat hubungan antara kejadian dismenore terhadap aktivitas belajar mahasiswi di prodi DIII Kebidanan STIK Immanuel
\end{abstract}

\section{Kata Kunci : Dismenore, Aktivitas belajar}

\section{PENDAHULUAN}

Remaja di definisikan sebagai masa peralihan dari masa kanak-kanak ke masa dewasa. Istilah remaja berasal dari kata latin yang berarti tumbuh menjadi dewasa. Anak dianggap dewasa apabila mampu mengadakan reproduksi. Batasan usia remaja menurut WHO adalah 12 sampai 24 tahun. Remaja akan mengalami pubertas yang ditandai dengan kematangan alat seksual dan terjadinya perubahan secara fisik, hormonal dan seksual serta mampu mengadakan reproduksi. Pada remaja putri masa pubertas diawali dengan adanya menstruasi. Bagi sebagian wanita, adakalanya menstruasi adalah hal yang menakutkan yang kehadirannya membuat rasa cemas manakala timbul rasa nyeri ketika menstruasi tiba. Kondisi ini dikenal sebagai nyeri menstruasi atau dismenorea (dysmenorrhoea, dismenore), yakni nyeri menstruasi yang memaksa wanita untuk istirahat atau berakibat pada menurunnya kinerja dan berkurangnya aktifitas sehari-hari, bahkan kadang bisa membuat tidak berdaya. Menurut Reeder (2013) dismenorea yakni nyeri menstruasi yang dikarakteristikan sebagai nyeri singkat sebelum atau selama menstruasi , nyeri ini berlangsung selamat satu sampai beberapa hari selama menstruasi yang sering dikeluhkan oleh wanita. Aktifitas belajar 
JURNAL SEHAT MASADA VOLUME XVI

menurut sardiman (2014) keaktifan merupakan kegiatan berupa fisik atau mental yaitu berbuat dan berfikir sebagai rangkaian yang tidak bisa dipisahkan. Jadi apabila seseorang mengalami Gejala psikis syndrom menstruasi maka akan menurunkan konsentrasi dan daya ingat. Gejala tersebut dipertegas oleh Emilia (2008) yang mengemukakan gejala syndrom premenstruasi yang paling terbanyak adalah berkurangnya mood (keinginan) dan berkurangnya aktivitas belajarnya.

Dismenorea yang dialami oleh remaja putri juga menjadi salah satu penyebab utama ketidakhadiran di sekolah. Selain menurunkan angka kehadiran $(69,7 \%)$ remaja putri yang mengalami dismenorea juga mengaku mengalami penurunan dalam prestasi akademik, penurunan konsentrasi $(72,7 \%)$ dan ketidakmapuan untuk menjawab pertanyaan dalam ujian (54,3\%). Lebih dari (60\%) responden mengaku hubungan sosialisasinya terganggu karena dismenorea (Rakhshaee, 2014). Menurut WHO (WHO) dalam penelitian Sulistyorini (2017), Angka kejadian dismenore cukup tinggi diseluruh dunia. Ratarata insidensi terjadinya dismenore pada wanita muda antara $16,8-81 \%$. Menurut Savitri (2015),di Indonesia angka kejadian dismenorea terdiri dari $54,89 \%$ dismenorea primer dan 9,36\% dismenorea sekunder.

Pada studi pendahuluan yang dilakukan peneliti di Prodi DIII Jurusan Kebidanan sebanyak 62 mahasiswi yang masih aktif mengikuti proses belajar mengajar ditemukan sebanyak 28 orang (48\%) mahasiswi yang mengalami dismenorea. Diantaranya mahasiswi yang mengalami kesulitan untuk berkonsentrasi saat belajar serta merasa lelah dan malas sepanjang hari, serta tidak ada tindakan khusus yang dilakukan oleh pihak kampus untuk mengurangi rasa nyeri yang dialami oleh mahaisiswi kecuali memberikan keringanan untuk beristirahat, oleh karena itu mahasiswa yang mengalami disemnorea tersebut memutuskan untuk tidak mengikuti perkuliahan pada saat mengalami dismenore. Hal tersebut berdampak pada angka kehadiran dan partisipasi minat mahasiswi untuk mengikuti proses belajar mengajar sehingga akan berakibat pada penurunan Aktivitas belajar mahasiswa.

\section{METODE PENELITIAN}

Jenis penelitian yang digunakan yaitu penelitian kuantitatif dengan desain cross sectional. Penelitian ini mempelajari Hubungan antara Dismenorea (independent) dengan Aktivitas Belajar (dependent), dimana lokasi penelitian dilakukan di Sekolah tinggi ilmu kesehatan Immanuel prodi DIII Kebidanan dengan tekhnik total sampling yaitu sebanyak 28 orang mahasiswi yang mengalami nyeri pada saat menstruasi. Tekhnik pengambilan sample yang digunakan adalah accidental sampling. Alat ukur yang digunakan dalam penelitian ini adalah Numeric Rating Scale (NRS) untuk mengetahui tingkat nyeri dalam dismenore dan kuesioner untuk mengetahui aktivitas belajar mahasiswa. Analisis bivariat dilakukan untuk mengetahui hubungan antara variabel, yaitu menghubungkan kejadian dismenorea dengan 
JURNAL SEHAT MASADA VOLUME XVI

aktivitas belajar. Analisis data diolah dengan SPSS versi 16 dengan uji statistic chi-square.

\section{HASIL PENELITIAN}

\section{A. Analisis Univariat}

Berdasarkan hasil pengumpulan data yang diambil pada bulan Juni sampai bulan Juli 2021 pada mahasiswa Prodi D3 Kebidanan STIK Immanuel yang berjumlah 28 orang, diperoleh data sebagai berikut :

\section{Tabel 1}

Distribusi Frekuensi Karakter Usia Mahasiswi Prodi D3 Kebidanan

\begin{tabular}{lcc}
\hline Usia & Frekuensi & Presentasi $(\%)$ \\
\hline$\leq 20$ & 23 & 82,1 \\
$>20$ & 5 & 17,9 \\
Total & 28 & 100 \\
\hline
\end{tabular}

Berdasarkan Tabel 1 sebagian besar responden memiliki usia kurang dari 20 tahun sebanyak 23 orang $(82,1 \%)$, dan sebanyak 5 orang memiliki usia kurang dari 20 tahun $(17,9 \%)$

\section{Tabel 2}

Distribusi Frekuensi intensitas Nyeri pada saat haid mahasiswi Prodi D3 Kebidanan

\begin{tabular}{lcc}
\hline Intensitas Nyeri & Frekuensi & Presentasi (\%) \\
\hline Nyeri Ringan & 8 & 28,6 \\
Nyeri sedang & 10 & 35,7 \\
Nyeri Berat & 10 & 35,7 \\
Total & 28 & 100 \\
\hline
\end{tabular}

Berdasarakan Tabel 2. sebagian besar responden memiliki intensitas nyeri berat sebanyak 10 orang $(35,7 \%)$, sebanyak 10 orang memiliki intensitas nyeri sedang $(35,7 \%)$ dan sebanyak 8 orang memiliki intensitas nyeri ringan $(28,6 \%)$

Tabel 3

Distribusi Aktivitas Belajar mahasiswi Prodi D3 Kebidanan

\begin{tabular}{lcc}
\hline Intensitas Nyeri & Frekuensi & Presentasi (\%) \\
\hline Aktivitas Belajar Terganggu & 11 & 28,6 \\
Aktivitas Belajar tidak Terganggu & 17 & 35,7 \\
Total & 28 & 100 \\
\hline
\end{tabular}

Berdasarakan Tabel 3 didapatkan sebanyak 11 orang $(39,3 \%)$ mengatakan terganggu aktivitas belajarnya pada saat mengalami dismenore dan sebanyak 17 orang $(60,7 \%)$ mengatakan tidak terganggu aktivitas belajarnya pada saat mengalami dismenore.

\section{B. Analisis Bivariat}

Tabel 4

Hubungan Dismenore dengan Aktivitas Belajar mahasiswi Prodi D3 Kebidanan

\begin{tabular}{lcccccc}
\hline Tingkat Dismenore & \multicolumn{2}{c}{$\begin{array}{c}\text { Aktivitas Belajar tidak } \\
\text { Terganggu }\end{array}$} & \multicolumn{2}{c}{$\begin{array}{c}\text { Aktivitas Belajar } \\
\text { terganggu }\end{array}$} & Total & $\%$ \\
\cline { 1 - 4 } & $\mathrm{N}$ & $\%$ & $\mathrm{~N}$ & $\%$ & & \\
\hline Nyeri Ringan dan sedang & 16 & 88,9 & 2 & 11,1 & 8 & 100 \\
Nyeri Berat & 1 & 10 & 9 & 90 & 10 & 100 \\
Total & 17 & 60,7 & 11 & 39,3 & 28 & 100 \\
\hline
\end{tabular}


Berdasarakan Tabel 4 didapatkan bahwa sebagian besar responden yang memiliki intensitas nyeri berat terganggu aktivitas belajarnya yaitu sebanyak (90\%), sedangkan responden yang mempunyai intensitas nyeri ringan dan sedang tidak terganggu aktivitas belajarnya $(88,9 \%)$, dan yang terganggu aktivitas belajarnya sebanyak $(11,1 \%)$.

Selanjutnya hasil penelitain dengan menggunakan uji chi square $\mathrm{p}$ Value 0,00 $<0,05$ sehingga dapat dikatakan ada hubungan antara dismenorea dengan aktivitas belajar pada mahasiswi prodi DIII Kebidanan.

\section{PEMBAHASAN}

\section{Dismenore}

Hasil penelitian yang dilakukan terhadap 28 orang mahasiswi prodi DIII Kebidanan STIK Immanuel Bandung dengan menggunakan Numeric Rating Scale (NRS) menunjukan bahwa sebanyak 8 orang $(28,6 \%)$ mahasiswa yang mengalami dismenore dengan intensitas nyeri ringan, sebanyak 10 orang (35,7\%)mahasiswa yang mengalami dismenore dengan intensitas nyeri sedang dan sebanyak 10 orang $(35,7 \%)$ mahasiswa yang mengalami dismenore dengan intensitas nyeri berat pada saat menstruasi. Menurut Reeder (2013) dismenorea adalah nyeri menstruasi yang dikarakteristikan sebagai nyeri singkat sebelum atau selama menstruasi, nyeri ini berlangsung selamat satu sampai beberapa hari selama menstruasi yang sering dikeluhkan oleh wanita. Intensitas nyeri yang ditimbulkan oleh dismenore mempunyai tingkatan nyeri yang berbeda-beda sesuai dengan apa yang dirasakan oleh mahasiswi pada saat menstruasi. Menurut Astrida (2012) yang membagi dismenore menjadi tiga tingkatan yaitu dismenore ringan, sedang dan berat. Ambang nyeri setiap orang pada saat menstruasi berbeda-beda yang dipengaruhi oleh faktor-faktor yaitu faktor endokrin, faktor penyakit, gaya hidup seseorang seperti merokok, kekurangan gizi, stress, status gizi, usia menarce dan aktivitas.

\section{Aktivitas Belajar}

Aktifitas belajar menurut Dimyati dan Mudjiono (2010) merupakan keaktifan peserta didik dalam kegiatan belajar untuk mengkonstruksi pengetahuan mereka sendiri. Setiap individu harus belajar aktif mengembangkan potensinya, Peserta didik dituntut untuk selalu memproses dan mengolah proses belajar yang didapat peserta didik. Untuk memunculkan proses belajar yang menarik, peserta didik harus berinteraksi dengan baik dalam proses pembelajaran. Hasil penelitian yang dilakukan terhadap 28 orang mahasiswi prodi DIII Kebidanan STIK Immanuel Bandung dengan menggunakan kuesioner menunjukan bahwa sebanyak 11 orang $(28,6 \%)$ mahasiswa terganggu aktivitas belajarnya ketika mengalami dismenore, dan sebanyak 17 orang $(35,7 \%)$ mahasiswa tidak terganggu aktivitasnya ketika mengalami dismenore. Dapat disimpulkan bahwa gangguan menstruasi yang sering terjadi pada mahasiswa dapat berpengaruh dan mencegah mahasiswi utuk dapat beraktivitas dengan baik. Banyak mahasiswi yang mengalami gangguan dalam menjalankan aktivitas belajar Jurnal Penelitian Kesehatan STIKes Dharma Husada Bandung 
dikarenakan mengalami dismenore pada saat proses pembelajaran sehingga membuat mahasiswi sulit untuk berkonsentrasi, hal tersebut akan berpengaruh terhadap prestasi mahasiswi di kampus. Aktifitas belajar menurut sardiman (2014) keaktifan merupakan kegiatan berupa fisik atau mental yaitu berbuat dan berfikir sebagai rangkaian yang tidak bisa dipisahkan. Jadi apabila seseorang mengalami Gejala psikis syndrom menstruasi maka akan menurunkan konsentrasi dan daya ingat. Gejala tersebut dipertegas oleh Emilia yang mengemukakan gejala syndrom premenstruasi yang paling terbanyak adalah berkurangnya mood (keinginan) dan berkurangnya aktivitas belajarnya. Dampak dari gangguan aktivitas tersebut adalah tingginya tingkat absen di sekolah maupun di tempat kerja, keterbatasan hidup sosial, perfoma akademik, serta aktivitas olahraganya.

\section{Hubungan Dismenore dengan Aktivitas belajar}

Berdasarkan hasil uji chi square menunjukan bahwa $\mathrm{p}<0,05(\mathrm{P}=0,00)$ artinya Ho ditolak dan Ha diterima sehingga dapat dikatakan ada hubungan antara dismenore dengan aktivitas belajar mahasiswi prodi DIII Kebidanan STIK Immanuel. Hasil penelitian ini menunjukan bahwa semakin berat tingkat nyeri dismenore maka aktivitas dari mahasiswa tersebut akan terganggu sehingga akan mempengaruhi prestasinya dalam proses akademik. Hal ini didukung oleh penelitian Alifah, dkk (2017) dengan hasil uji korelasi rank spearman menunjukan bahwa terdapat hubungan yang signifikan antara kejadian dismenore dengan aktivitas belajar $(0,000<0,05)$ di kelas XI SMA Negeri 52 Jakarta, dari hasil penelitiannya didapatkan bahwa mahasiswi terganggu aktivitasnya dikarenakan adanya dismenore yang berdampak pada fisik seperti cepat lelah dan tidak bersemangat maupun dari segi psikologis seperti sulit berkonsentrasi karena rasa ketidaknyamanan yang timbul pada saat dismenore. Sebuah penelitian mengungkapkan bahwa mahasiswa dengan dismenore akan mengalami efek negatif terhadap aktivitas belajarnya, dimana mahasiswa sebagian besar kehilangan konsentrasinya pada saat belajar dan tidak berpartisipasi didalam kelas. Bisa dilihat dari tabel 1.24 mahasiswi yang mengalami dismenore dengan tingkat nyeri berat sebanyak 9 orang (90\%) terganggu aktivitasnya, sedangkan mahasiswi yang mengalami dismenore dengan tingkat nyeri ringan dan sedang masih ada 2 orang $(11,1 \%)$ yang terganggu juga aktivitas belajarnya walaupun sebanyak 16 orang $(88,9 \%)$ tidak terganggu aktivitas belajarnya. Hal ini dikarenakan semakin berat tingkat nyeri seseorang yang mengalami dismenore maka akan semakin terganggu aktivitas belajarnya dan semakin ringan tingkat nyeri dismenore seseorang maka seseorang tersebut masih bisa melakukan aktivitas belajarnya dengan baik.

\section{SIMPULAN}

Terdapat hubungan yang signifikan antara dismenore dengan aktifitas belajar mahasiswa prodi DIII Kebidanan STIK Immanuel . Berdasarkan hasil uji chi square menunjukan bahwa $\mathrm{P}<0,05(\mathrm{p}=0,00)$ artinya Ho ditolak Jurnal Penelitian Kesehatan STIKes Dharma Husada Bandung 
JURNAL SEHAT MASADA VOLUME XVI

dan Ha diterima, sehingga dapat dikatakan ada hubungan antara kejadian dismenore dengan aktivitas belajar mahasiswa prodi DIII Kebidanan STIK Immanuel Bandung

\section{DAFTAR PUSTAKA}

Alimuddin Amaliya (2017). Hubungan Dismenore dengan aktivitas belajar mahasiswa prodi DIV Kebidanan poltekes kemenkes. Kendari

Alifah, Yunus, dkk (2017) Hubungan antara dismenore terhadap aktivitas belajar pada siswi kelas XI SMA negeri 52. Jakarta

Andiarna Funsu (2012). Tesis. Hubungan sindrom premenstruasi dan dismenore dengan motivasi belajar pada mahasiswa DIII Kebidanan Stikes Karya Husada. Kediri

Anurogo, Dito\& Wulandari,A 2011, Cara Jitu Mengatasi Nyeri Haid, CV Andi Offset, Jogjakarta

A.M, Sardiman. 2014. Interaksi dan Motivasi Belajar Mengajar. Jakarta: Rajawali Pers

Asma'ulludin, Abdul Karim. 2016. Kejadian Dismenore berdasarkan Karakteristik Orang dan Waktu serta Dampaknya pada Remaja Pustri SMA dan Sedarajat di Jakarta Barat tahun 2015.Fakultas Kedokteran dan Ilmu Kesehatan Universitas Islam Negeri Syarif Hidayatullah Jakarta

Agus Riyanto, (2011). Aplikasi Metodologi Penelitian Kesehatan. Nuha. Medika Yogyakarta

Arifin. 2011. Metode Penelitian Kualitatif, Kuantitatif, dan R \& D. Bandung: Alfabeta.

Dimyati \& Mudjiono. 2013. Belajar Dan Pembelajaran. Jakarta: Rineka Cipta

Hanum Diyana (2019) Hubungan dismenore dengan aktivitas belajar mahasiswa akademi kebidanan delima persada, volume II No.01. Gresik
Lusianah, Indaryani, E. D., \& Suratun. (2012). Prosedur Keperawatan (p. 287). Jakarta: Trans Info Media.

Nanda. (2015). Diagnosis Keperawatan Definisi \& Klasifikasi 2015-2017 Edisi 10 editor T Heather Herdman, Shigemi Kamitsuru. Jakarta: EGC

Notoatmodjo . 2012. Metode Penelitian Kesehatan. Jakarta : Rineka Cipta

Nugroho, T. (2012). Obsgyn : Obstetri dan ginekologi. Yogyakarta : Nuha Medika

Reeder, Martin \&Koniak-Griffin. 2013. Keperawatan maternitas kesehatan wanita, bayi \& keluarga Edisi 8 Vol 1. Jakarta : EGC

Sanday Septi, Kusuma, dkk (2019) Hubungan intensitas nyeri dismenore dengan aktivitas belajar pada remaja putri di SMAN I Banyuwangi. Jurnal cakrawala promkes vol I No 2, P-ISSN, Yogyakarta

Sarwono, Sarlito W (2013). Psikologi Remaja. Jakarta: Rajawali Pers

Setiawan, Linda, dkk (2018) Hubungan dismenore dengan aktivitas belajar sehari hari pada remaja putri kelas VIII di SMPN 3. Jurnal delima harapan volume 9 No 8. Pulung

Sulistyorini, S., Santi, S. M., \& Ningsih, S. S. (2017). Faktor-faktor yang mempengaruhi kejadian disminorhea primer pada siswi sma pgri 2 palembang. journalstikesmp.ac.id, volume 5

Sudjana, Nana. 2013. Dasar-Dasar Proses Belajar Mengajar. Bandung: Sinar Baru Algensindo.

Sugiyono. 2010. Metode Penelitian Pendidikan Pendekatan Kuantitatif, kualitatif, dan $R \& D$. Bandung: Alfabeta

Widyastuti, Y., dkk. 2009. Kesehatan Reproduksi. Yogyakarta: Fitrimaya.

Wratsongko, M. 2015. Senam Ergonomik dan Pijat Getar. Jakarta: Gramedia 